\title{
Property loss potentials for European midlatitude storms in a changing climate
}

Article

Published Version

Leckebusch, G. C., Ulbrich, U., Fröhlich, L. and Pinto, J. G. (2007) Property loss potentials for European midlatitude storms in a changing climate. Geophysical Research Letters, 34 (5). L05703. ISSN 0094-8276 doi:

https://doi.org/10.1029/2006GL027663 Available at https://centaur.reading.ac.uk/32789/

It is advisable to refer to the publisher's version if you intend to cite from the work. See Guidance on citing.

Published version at: http://dx.doi.org/10.1029/2006GL027663

To link to this article DOI: http://dx.doi.org/10.1029/2006GL027663

Publisher: American Geophysical Union

All outputs in CentAUR are protected by Intellectual Property Rights law, including copyright law. Copyright and IPR is retained by the creators or other copyright holders. Terms and conditions for use of this material are defined in the End User Agreement.

\section{www.reading.ac.uk/centaur}

\section{CentAUR}

Central Archive at the University of Reading 
Reading's research outputs online 


\title{
Property loss potentials for European midlatitude storms in a changing climate
}

\author{
Gregor C. Leckebusch, ${ }^{1}$ Uwe Ulbrich, ${ }^{1}$ Luise Fröhlich, ${ }^{2,3}$ and Joaquim G. Pinto ${ }^{2}$ \\ Received 25 July 2006; revised 17 November 2006; accepted 23 January 2007; published 2 March 2007.
}

[1] Winter storms of the midlatitudes are an important factor for property losses caused by natural hazards over Europe. The storm series in early 1990 and late 1999 led to enormous economic damages and insured claims. Although significant trends in North Atlantic/European storm activity have not been identified for the last few decades, recent studies provide evidence that under anthropogenic climate change the number of extreme storms could increase, whereas the total number of cyclones may be slightly reduced. In this study, loss potentials derived from an ensemble of climate models using a simple storm damage model under climate change conditions are shown. For the United Kingdom and Germany ensemble-mean stormrelated losses are found to increase by up to $37 \%$. Furthermore, the interannual variability of extreme events will increase leading to a higher risk of extreme storm activity and related losses. Citation: Leckebusch, G. C., U. Ulbrich, L. Fröhlich, and J. G. Pinto (2007), Property loss potentials for European midlatitude storms in a changing climate, Geophys. Res. Lett., 34, L05703, doi:10.1029/ 2006 GL027663.

\section{Introduction}

[2] Over the Northwest Atlantic deep cyclones originate, travel eastwards and can affect the European continent. Surface wind storms related to these deep cyclones are connected to mid-tropospheric transient eddies, the latter contributing significantly to the meridional energy transport. Due to the balance between latitudinal differential energy input by absorbed shortwave solar radiation and output by outgoing longwave radiation, the large-scale oceanic and atmospheric circulations act as energy transport mechanisms from equatorial latitudes to polar regions. Thus, the occurrence of cyclone systems and storms is a vital part of the earth's climate system.

[3] Only a small proportion of the total number of cyclones which develop produce gale force wind speeds and are thus called storms. Although a clear positive trend in North Atlantic/European storm activity is not identifiable during the last few decades, recent studies provide evidence that under anthropogenic climate change the number of extreme storms could increase, whereas the total number of

\footnotetext{
${ }^{1}$ Institut für Meteorologie, Freie Universität Berlin, Berlin, Germany.

${ }^{2}$ Institut für Geophysik und Meteorologie, Universität zu Köln, Cologne, Germany.

${ }^{3}$ Institut für Physik der Atmosphäre, Johannes Gutenberg-Universität Mainz, Mainz, Germany.
}

Copyright 2007 by the American Geophysical Union. 0094-8276/07/2006GL027663 cyclones may be slightly reduced [e.g., Leckebusch et al., 2006; Lambert and Fyfe, 2006; Leckebusch and Ulbrich, 2004]. Nevertheless, in terms of insured losses, nine out of the ten most expensive European weather-related hazards were caused by wind storms. During early 1990 a series of severe storms led to enormous economic damages of approximately US- $\$ 14.2 \mathrm{bn}$, including US- $\$ 9.8$ bn insured claims (1990 prices, Berz [2005]). The most expensive wind storm event, since the 1950s (the beginning of systematic insurance industry records), has been Lothar in December 1999 with an estimated insured loss of \$5.9 bn (Germany, France, Switzerland mainly affected). The only exception is the central European flood in summer 2002 with insured costs about \$3.4 bn [Reinhard, 2005]. Total economic losses for both these events are estimated at around $\$ 11.5$ bn and $\$ 16.0 \mathrm{bn}$, respectively. Studies based on insurance industry catastrophe models estimate an increase in insured wind-related losses from extreme European wind storms due to climate change by $\$ 2-2.5$ bn, representing a 5\% increase [Association of British Insurers, 2005, available at http://www.abi.org.uk/Display/File/Child/552/ Financial_Risks_of_Climate_Change.pdf].

\section{Approach}

[4] In this study the changes in loss potentials under anthropogenic climate conditions are assessed from an ensemble of 4 "state-of-the-art" global climate models (GCMs): HadCM3 (Hadley Centre Coupled Model version 3), HadAM3P (Hadley Centre Atmospheric Model version P), ECHAM4/OPYC3 (European Centre Hamburg Version 4/Ocean in isoPYCnical coordinates Version 3), and ECHAM5-OM1 (European Centre Hamburg Version 5/Max Planck Institute Version - Ocean Model Version 1). Using a multi-model ensemble is favourable compared to a singlemodel ensemble, as a better sampling of unavoidable uncertainties in the computational representation of the dynamic equations is possible [Palmer and Räisänen, 2002; Palmer, 2001]. The horizontal resolution varies: $3.75^{\circ} \times 2.5^{\circ}$ for $\mathrm{HadCM} 3,1.875^{\circ} \times 1.875^{\circ}$ for HadAM3P, T42 (approximately $2.8^{\circ} \times 2.8^{\circ}$ ) for ECHAM4, and T63 (appr. $2.0^{\circ} \times 2.0^{\circ}$ ) for ECHAM5. Although regional climate models $(\mathrm{RCM})$ provide more detailed information on finer-grid scales, it is reasonable to first identify the climate change signal directly from the large-scale model output. As studies have shown [e.g., Leckebusch et al., 2006], RCMs depend much more on the driving GCM than on the assumed future scenario.

[5] Storm damage potentials are estimated by a regression model based on daily maximum $10 \mathrm{~m}$ wind speeds (i.e. the daily maximum of the simulated wind speeds over all 


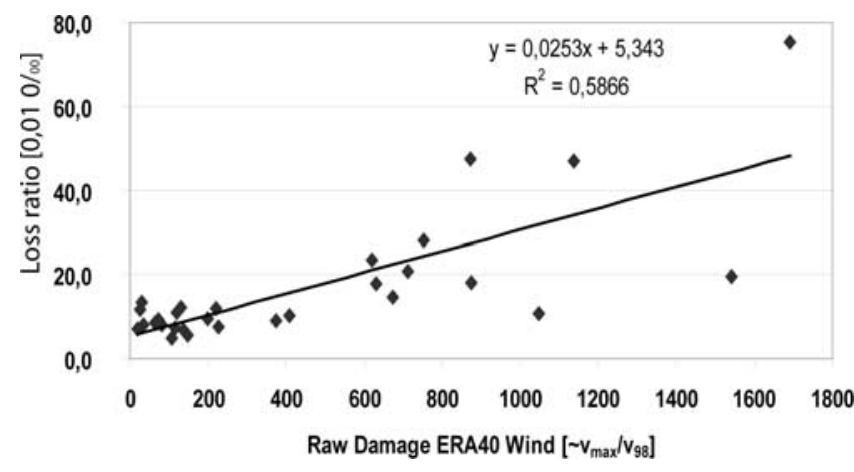

Figure 1. Regression between ERA40 derived "raw damage" values and loss ratios for Germany from the German Insurance Association (GdV).

integration steps of the model per day) and actual loss values [Klawa and Ulbrich, 2003]. The only exception from this is ECHAM4/OPYC3, for this model the maximum out of 4 instantaneous values per day $(00,06,12,18$ UTC) were used due to data availability. Calculations based on the maximum out of 4 instantaneous values for ECHAM5/OM1 have shown that the resulting loss ratios underestimate those numbers derived from the maximum of each integration time step, only slightly by $1-3 \%$.

[6] The model is based on the assumption that damages occur only if the surface wind speed exceeds a specific locally defined threshold. Studies using meteorological station data as well as NCEP-Re-analysis data have revealed that the 98th percentile wind speed is a reasonable value for this threshold [Klawa and Ulbrich, 2003; Klawa, 2001]. To account for local adaptation to the wind climate, damages are assumed to be proportional to the difference between the actual wind value $\left(\mathrm{v}_{\max }\right)$ and the particular 98th percentile $\left(\mathrm{v}_{98}\right)$, thus the wind value is scaled by the local percentile value. From physical reasons the cube of wind speed is proportional to the advection of kinetic energy. Moreover, some empirical evidence exists for a cubic damage-wind relation [Munich Re, 1993]. Additionally, loss values depend on the amount of values in an affected area. The population density (p) is used as a reasonable proxy. Thus, the applied loss function is given by:

$$
\text { loss } \approx p\left(\frac{v_{\max }}{v_{98}}-1\right)^{3} \quad \text { for } \mathrm{v}_{\max }>\mathrm{v}_{98}
$$

These wind-based "raw-damage" values are calculated for ECMWF-Re-analysis (ERA40: 1960-2000) [Uppala et al., 2005] daily maximum wind data (i.e. the maximum out of 4 values per day), accumulated to annual values, and fitted via linear regression to real annual damage values (Figures 1 and 2). The ECMWF-Re-analysis data are used here as surrogate for observational data. The annual sums of insured losses are provided by the Gesamtverband der Deutschen Versicherer (German Insurance Association, hereafter GdV) for the years from 1970-1999 for Germany and for the UK by the Association of British Insurers (ABI) for the period 1988-2003. The resulting regression coefficients are then applied to the climate model data. For the population density data the UN $1^{\circ} \times 1^{\circ}$ gridded data were used (available at http://grid2.cr.usgs.gov/metadata/unep/GRID/ GLPOP90.html). Normalized values to the amount of insured values are more important than absolute values which are affected, for example, by variable inflation rates. Therefore, loss potentials are given in terms of the loss ratio, defined as the ratio between insured claims and totally insured values given in $0.01 €$ per $1000 €$.

\section{Loss Potentials for Recent Climate and Changed Climate Conditions}

[7] For a baseline period with recent anthropogenic greenhouse gas concentrations, the model-based loss ratios are validated against values derived from ECMWF-Reanalysis. The time average values for Germany and the UK are given in Table 1. As can be seen, the model-based mean loss ratios are in the same range as ERA40 values. The largest deviation is simulated by ECHAM4/OPYC3 for Germany (25\% underestimation). The variability of loss ratios for Germany is well simulated, whereas for the UK

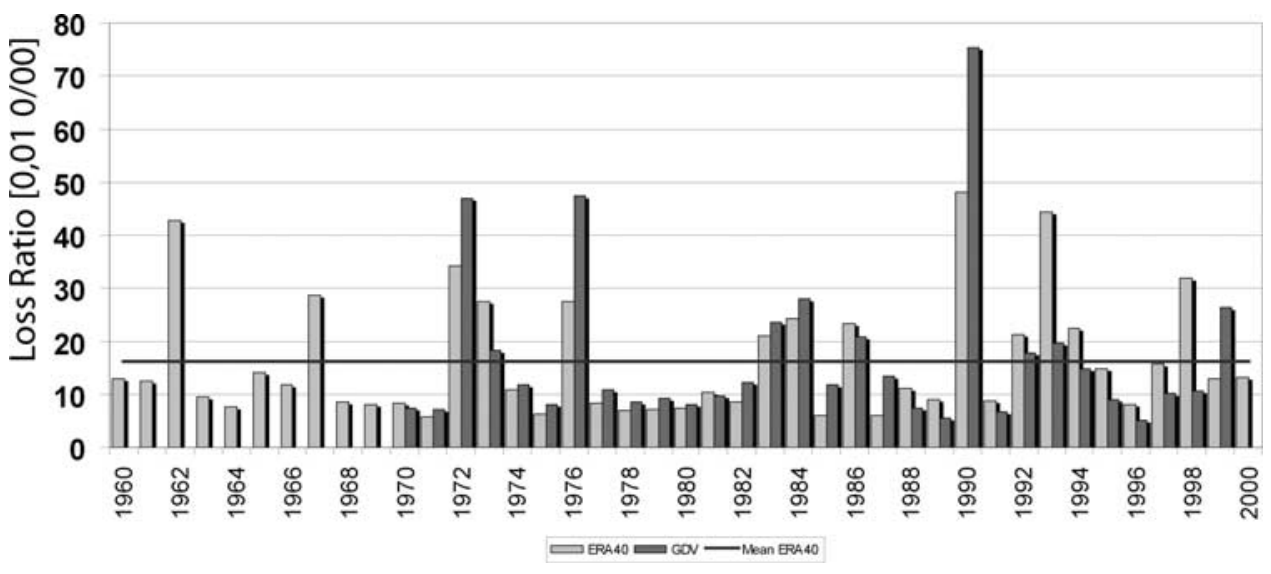

Figure 2. Loss ratio for Germany in 1 cent per 1000€. ECMWF-ERA40 derived values (grey), real loss ratios provided by the German Insurance Association (GdV) for the years 1970-1999 (black). 
Table 1. Loss Ratio Validation for Germany and United Kingdom ${ }^{\mathrm{a}}$

\begin{tabular}{ccccccc}
\hline & Loss Ratio & ERA40 & HadCM3 & HadAM3P & ECHAM4/OPYC3 & ECHAM5/OM1 \\
\hline GER & AVE & 16.98 & 17.16 & 15.54 & 12.97 & 19.56 \\
& STD & 13.27 & 12.31 & 14.65 & 9.17 & 14.26 \\
UK & AVE & 12.77 & 12.79 & 12.33 & 13.55 & 6.76 \\
& STD & 9.10 & 6.8 & 9.31 & 6.85 \\
\hline
\end{tabular}

${ }^{\mathrm{a}}$ Values are given in $0.01 €$ per 1000€. Baseline period for Hadley-Centre models, 1960-1989; ECHAM4, 1890-1909; ECHAM5, 1960-2000; and ERA40, 1960-2000.

the interannual variability is not fully captured by the models.

[8] In order to detect the climate change signal due to anthropogenic influences, model simulations forced by prescribed boundary conditions given through the IPCC-SRES A2 (HadCM3, HadAM3P, ECHAM5/OM1) and IS92a scenarios (ECHAM4/OPYC3) were analysed [Intergovernmental Panel on Climate Change, 1994, 2001]. The climate change signal is defined as the difference of the means between a future time period (scenario period, 2070-2099; ECHAM5/OM1: 20602100) and the baseline periods (Hadley Centre models: 1960-1989, ECHAM4: 1890-1909, ECHAM5: $1960-$ 2000). In the used simulation with ECHAM4/OPYC3 the anthropogenic GHG forcing is prescribed using observed data between 1860 and 1990, and the IS92a scenario afterwards. The model simulation is initialized with present-day values rather than pre-industrial ones. This causes a warm bias in the initial state of the scenario run which is maintained throughout the simulation. As the GHG concentrations increases slowly during the first decades of the run, the period between 1880 and 1930 represents present-day conditions and the period from 1890 to 1909 is used here as the 'control period'. Further details on this simulation are given in Roeckner et al. [1998], Knippertz et al. [2000], and Pinto et al. [2006]. The "raw-damage" values were calculated in two ways: firstly, the local 98th percentile value of the daily maximum wind speed was calculated for the baseline period and scenario period separately. Thus, local adaptation to climate change is taken into account. For example if the wind speeds increase and $\mathrm{V}_{98}$ increases, damages occur only above the higher threshold. This implies that adaptation to changed local wind speeds has already taken place. Secondly, the 98th percentile value of the daily maximum wind speed has been fixed to the baseline value, consequently no adaptation to climate change is considered, and the pure effect of anthropogenic change is detected. In Tables 2 and 3, the climate change signals for Germany and the United Kingdom are presented. For consistency, the model-based values shown for the UK are calculated via the regression coefficients derived from the German damage data. Sensitivity studies have shown that the same magnitude and tendency of the resulting mean loss changes and its standard deviations is achieved by applying the regression derived from British damage data. The regression between UK wind and damage data is given by $y=0.6062 x+472,28$. The $R 2$ value is 0.3635 . Please note, UK losses are given in cash prices total for the time period from 1988 to 2003 (Units: 1 Million GBP). Thus, the regression coefficients for the German wind-damage relationship and the UK counterpart are not directly comparable, as German damage values are given in loss ratios (Units: 1 Euro cent per 1000 Euro). This provides evidence that the regression coefficients deduced from the region Germany are applicable also to other regions with similar infrastructure. For both the UK and Germany, considering no adaptation to changed wind climate, the ensemble average potential loss ratios increase by approximately $37 \%$ and $21 \%$, respectively. Whereas three models show increases in the same range with respect to the mean value, HadAM3P reveals less pronounced changes and even negative changes for Germany. The range of achieved values is related to the fact that damages follow the cube of the excess of the local wind speed threshold, thus they are very sensitive to changes of the percentile values or the occurrence of rare extreme events. Negative changes in HadAM3P in Germany accompanied by positive changes over the UK, are mainly due to the fact that the horizontal distribution of changes in $\mathrm{v}_{98}$ are slightly negative over Germany, and positive over the UK which is again based on moderate differences in the occurrence of extreme cyclones in the model simulations investigated [cf. Leckebusch et al., 2006].

[9] Taking adaptation into account, the changes are less uniform and mainly depend on the climate model investigated. Thus, a clear trend is not identifiable as model-tomodel variability is high, revealing a high level of uncertainty, e.g. in the exact position of areas of changes in the 98th percentile of the daily maximum wind speed relative to the investigated regions. Nevertheless, positive changes up

Table 2. Climate Change Signal for Germany ${ }^{\mathrm{a}}$

\begin{tabular}{|c|c|c|c|c|c|}
\hline Loss Ratio & HadCM3 & HadAM3P & ECHAM4/OPYC3 & ECHAM5/OM1 & EnsembleAverage \\
\hline Average with adaptation & -10.6 & -20.9 & +4.4 & -5.3 & -8.1 \\
\hline Average without adaptation & +43.9 & -15.0 & +28.4 & +24.7 & +20.5 \\
\hline STD with & -10.2 & -61.8 & -2.6 & +44.4 & -7.6 \\
\hline STD without & +72.3 & -54.2 & +25.1 & +97.3 & +35.1 \\
\hline
\end{tabular}

${ }^{\mathrm{a}}$ Climate change signal of the loss ratio in \%: Difference between scenario and baseline period. 
Table 3. Climate Change Signal for United Kingdom ${ }^{\mathrm{a}}$

\begin{tabular}{|c|c|c|c|c|c|}
\hline Loss Ratio & HadCM3 & HadAM3P & ECHAM4/OPYC3 & ECHAM5/OM1 & EnsembleAverage \\
\hline Average with adaptation & +22.4 & -1.9 & -9.1 & +2.8 & +3.6 \\
\hline Average without adaptation & +79.9 & +8.0 & +20.5 & +38.4 & +36.7 \\
\hline STD with & +113 & -4.8 & -4.6 & +55.9 & +39.9 \\
\hline STD without & +233 & +8.9 & +42.2 & +148 & +108 \\
\hline
\end{tabular}

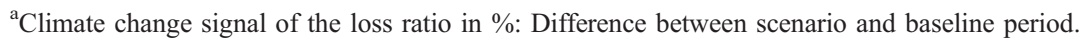

to nearly $23 \%$, derived from a single simulation, are possible. Changes in the standard deviation for both regions are mainly positive, documenting an increase in potential interannual variability of the occurrence of extreme wind events. More important than the change of the climatological mean values itself, positive changes in interannual variability could lead to a much higher risk in the occurrence of outliers affecting social and industrial risk management strategies.

\section{Conclusion}

[10] The results indicate a high risk of increasing loss potential for well developed western Central European regions if no adaptation to anthropogenic climate change is considered, and partly reduced risk if adaptation is taken into account, depending on the geographical region and the model investigated. This should provide additional motivation for the initiation of prevention measures today, and further development of public and private risk adaptation strategies.

[11] Admittedly, a larger ensemble of climate models and the investigation of RCMs are needed to increase the credibility and applicability of the results presented. Nevertheless, by applying this simple storm damage model to climate simulations it has been demonstrated that reasonable results are achieved for recent conditions when compared to observational data sets. Most of the intermodel variability in the results for future scenarios does not originate from the damage model itself, but from the different responses of the climate models to anthropogenic climate change. Additionally, by increasing the spatial and temporal resolution of climate models the capability of reproducing extreme events should increase. Especially for RCMs, this could lead to a better representation of the upper tail of the frequency distribution for the occurrence of extreme events, if a gust parameterization is included, for example. Thus, it will be very useful to compare the results from GCMs with those achieved from dynamical downscaling in future studies.

[12] Acknowledgments. This work was supported by the European Union programme Energy, Environment and Sustainable Developmen under contract EVK2-CT-2001-00118 (MICE). We acknowledge the provision of annual loss data by the German Insurance Association GdV and Andrew Dlugolecki. We acknowledge the international modelling groups for providing their data for analysis, the Program for Climate Model Diagnosis and Intercomparison (PCMDI) for collecting and archiving the model data, the JSC/CLIVAR Working Group on Coupled Modelling (WGCM) and their Coupled Model Intercomparison Project (CMIP) and Climate Simulation Panel for organizing the model data analysis activity, and the IPCC WG1 TSU for technical support. The IPCC Data Archive at Lawrence Livermore National Laboratory is supported by the Office of Science, U.S. Department of Energy.

\section{References}

Association of British Insurers (2005), Financial risks of climate change, summary report, Assoc. of Br. Insurers, London.

Berz, G. (2005), Natural catastrophes and climate change-The insurance industry's concerns and options for action, in Weather Catastrophes and Climate Change-Is There Still Hope for Us?, pp. 218-223, pg Verlag, Munich, Germany.

Intergovernmental Panel on Climate Change (1994), Climate Change, 1994: Radiative Forcing of Climate Change and an Evaluation of the IPCC IS92 Emission Scenarios, edited by J. T. Houghton et al., Cambridge Univ. Press, New York.

Intergovernmental Panel on Climate Change (2001), Climate Change 2001 : The Scientific Basis, edited by J. T. Houghton et al., Cambridge Univ. Press, New York.

Klawa, M. (2001), Extreme Sturmereignisse in Deutschland: Entwicklung, Zusammenhang mit der Nordatlantischen Oszillation und Auswirkungen auf die Versicherungswirtschaft, Ph.D. thesis, Mitt. 146, Inst. für Geophys. und Meteorol., Univ. zu Köln, Cologne, Germany.

Klawa, M., and U. Ulbrich (2003), A model for the estimation of storm losses and the identification of severe winter storms in Germany, Nat. Hazards Earth Syst. Sci., 3, 725-732.

Knippertz, P., U. Ulbrich, and P. Speth (2000), Changing cyclones and surface wind speeds over the North Atlantic and Europe in a transient GHG experiment, Clim. Res., 15, 109-122.

Lambert, S. J., and J. C. Fyfe (2006), Changes in winter cyclone frequencies and strengths simulated in enhanced greenhouse warming experiments: Results from the models participating in the IPCC diagnostic exercise, Clim. Dyn., 26, 713-728.

Leckebusch, G. C., and U. Ulbrich (2004), On the relationship between cyclones and extreme windstorm events over Europe under climate change, Global Planet. Change, 44, 181-193.

Leckebusch, G. C., B. Koffi, U. Ulbrich, J. G. Pinto, T. Spangehl, and S. Zacharias (2006), Analysis of frequency and intensity of European winter storm events from a multi-model perspective, at synoptic and regional scales, Clim. Res., 31, 59-74.

Munich Re (1993), Winterstürme in Europa, Münchener RückversicherungsGes., Munich, Germany.

Palmer, T. N. (2001), A nonlinear dynamical perspective on model error: A proposal for non-local stochastic-dynamic parameterisation in weather and climate prediction models, Q. J. R. Meteorol. Soc., 127, 279-304.

Palmer, T. N., and J. Räisänen (2002), Quantifying the risk of extreme seasonal precipitation events in a changing climate, Nature, 415, 512514.

Pinto, J. G., T. Spangehl, U. Ulbrich, and P. Speth (2006), Assessment of winter cyclone activity in a transient ECHAM4-OPYC3 GHG experiment, Meteorol. Z., 15, 279-291.

Reinhard, J. (2005), Good data-The be-all and end-all for underwriters, in Weather Catastrophes and Climate Change-Is There Still Hope for Us?, pp. 244-249, pg Verlag, Munich, Germany.

Roeckner, E., L. Bengtsson, J. Feichter, J. Lelieveld, and H. Rhode (1998), Transient climate change simulations with a coupled atmosphere-ocean GCM including the tropospheric sulfur cycle, Rep. 266, Max Planck Inst. für Meteorol., Hamburg, Germany.

Uppala, S. M., et al. (2005), The ERA-40 re-analysis, Q. J. R. Meteorol. Soc., 131, 2961-3012, doi:10.1256/qj.04.176.

L. Fröhlich, Institut für Physik der Atmosphäre, Johannes GutenbergUniversität Mainz, D-55099 Mainz, Germany.

G. C. Leckebusch and U. Ulbrich, Institut für Meteorologie, Freie Universität Berlin, Carl-Heinrich-Becker-Weg 6-10, D-12165 Berlin, Germany. (gcl@met.fu-berlin.de)

J. G. Pinto, Institut für Geophysik und Meteorologie, Universität zu Köln, Kerpener Strasse 13, D-50937 Köln, Germany. 